\title{
Compatibility of municipal services based on service similarity
}

\begin{abstract}
The aim of this article is to propose and examine a quantitative method of determining the degree of compatibility between municipal services. Provision of services and facilities maintenance are usually two biggest expenditures of local governments. Traditionally, facilities host only one service, whereas the challenge and opportunity lies in combining various, compatible services and offering them together under one roof. Such a combination decreases municipal expenditure and has a strong positive impact on the general service quality. For this purpose, we take advantage of the City-block distance formula to calculate the degree of compatibility between municipal services. The method is examined and discussed on a sample of 30 real municipal services. This allows us to find possible combinations of strongly compatible services that should be offered together in MultiService Facilities and, at the same time, avoid an unwanted combination of services that are incompatible.
\end{abstract}

\section{KEY WORDS}

Municipal services; public services; service compatibility; service similarity; facility optimization; spatial optimization.

\section{INTRODUCTION}

The delivery of public services and facilities maintenance is a critical function of local governments (Zolnik et al., 2010). It is a key aspect of city management due to its direct influence on city competitiveness and citizens' quality of life (Lee \& Lee, 2014). Consequently, it is also usually the most important expenditure of public administration due to its social function. Despite this, recent studies suggest that public services and facilities are in many cases poorly managed (Gonzalez, Llopis \& Gasco, 2013; Kwok \& Warren 2005). This is because for many years innovation research has been focused on the industrial sector, 
whereas public services have received little attention (Gonzalez, Llopis \& Gasco, 2013). In addition Tan, Koray and Baum (2008) report that all urban activities are unsustainable by definition because they consume resources. To that end, Cosgrave, Tryfonas and Crick (2014) suggest that the solution to this problem should be in seeking to improve the quality of services at lower resource costs. Therefore, we theorize that in an economic downturn a reduction of resources used for the provision of public services should be the fundamental element of the municipal optimization strategy.

Dobbelsteen and Wilde (2004) remark that optimization should start from a reduction in the demand for space. At the city level significant savings may be achieved through a more efficient adjustment of the surfaces used for public services provision. According to Neirotti et al. (2014) Information and Communication Technologies play an important role in this issue. Specifically, the emergent practice of service virtualization that forms a part of egovernment initiatives contributes to, inter alia, efficient management and cost reduction (World Bank, 2015). Services available online enable citizens to communicate and interact with city representatives without the need of visiting the appropriate facility personally. This, in a direct way, releases the space occupied especially by services, where citizen attention zones are significant. Moreover, virtual services decrease the number of workplaces due to automatization processes. However, in spite of this not all services can be virtualized. Sport, social or cultural are types of services that require in person participation. Others can be virtualized only partially, for example a basic health care consultation can be provided online; more specific treatment requires a specialized facility. Furthermore, even in so-called highly developed countries the problem of a Digital Divide exists, and prevents services from being fully virtualized. For these reasons service virtualization, however advantageous, does not solve the issue of conserving physical space completely, other simultaneous actions are necessary.

Marsal-Llacuna, Leung and Ren (2011) suggest that Multi-Service Facilities (MSF) can be a response to this problem since they reduce the amount of urban land necessary for public services provision and decrease their cost. Consequently, we are convinced that the essential step for public resource saving is a rewarding combination of compatible services in the facility building. Such a solution permits more than one activity to take place at the same 
time and location (Batty et al., 2004). Furthermore, efficient use of already available resources makes this approach economically sustainable because it increases the occupation rate implying that more people use the same area, or the same number of users use a smaller area (Dobbelsteen \& Wilde, 2004).

These considerations lead us to formulate the following hypothesis: Is it possible to establish the degree of compatibility between public services for their advantageous combination in MSF?

\subsection{Municipal services}

Public services are essential for a city to properly function. In general terms they are services provided by administrations of different levels (state, regional, municipal) in exchange for taxes. Thacker (2009) defines more precisely that public service is a piece of work performed by the public administration on behalf of the citizens. A general term of public service is sometimes substituted by others, corresponding to administrations of different levels: local, municipal or urban service. Here we are exclusively focused on services that are a municipal responsibility. Moreover, we consider only these services that require a physical space to be offered - a facility.

\subsection{Facilities}

A public facility in this frame of reference is a building intended for the provision of public services. Bennett and Iossa (2006) define two stages of the public facilities development process: building and management. Building a new facility is an easier way to respond to current social needs because the number of constraints is relatively low. Such an approach allows services to be very carefully planned and eventually obtain a good quality results. However, it is also expensive and difficult to execute, especially in an economic downturn. Hence, we mainly focus on the facility management stage and postulate that the challenge is to intentionally repurpose existing facilities by retrofitting them with other, compatible services.

\subsection{Service - facility relationship}

Service and facility are two concepts that are often confused. It is probably a consequence of mental shortcuts commonly used in everyday language. For instance, it is common to hear people speaking of a school. In fact, a school is a mental shortcut encompassing two concepts: 
a building (container) and a service of education (content) (Marsal-Llacuna, Leung \& Ren, 2011). It is of crucial importance to distinguish these two components, as summarized in table 1 .

\begin{tabular}{|l|l|}
\multicolumn{1}{|c|}{ SERVICE } & \multicolumn{1}{|c|}{ FACILITY } \\
\hline$\bullet$ Activity/Process & $\bullet$ Building \\
$\bullet$ Content & $\bullet$ Container \\
$\bullet$ Intangible & $\bullet$ Physical \\
$\bullet$ Primordial & $\bullet$ Secondary \\
\hline
\end{tabular}

Table 1 Comparison of two concepts: a service and a facility.

To sum it up: a service is an intangible process or activity that constitutes the content of a physical container - a building. A service is primordial, while a facility is secondary - it exists only to provide appropriate conditions for service offering.

Based on a research encompassing scientific papers, organization charts and different city administrations we discovered three types of relationships between services and facilities. The most common is a one-to-one relationship where a service is offered in one facility and a facility hosts only one service. In such cases a service is usually identified with a facility and mental shortcuts are created, e.g. a school refers to the building as well as the service of education. Another case occurs when a service requires more than one facility, e.g. a waste management service takes place in a waste treatment facility and recycling plant. The last variant takes place when more than one service is offered in one facility (MSF), for example, social youth service, multimedia library service and gym service are offered together in a community centre facility.

\subsection{Compatibility}

The Oxford Dictionary provides a general definition of compatibility, which is: "a state in which two things are able to exist or occur together without problems or conflict" (Compatibility, 2015). The fundamental question that emerges is, when are some "things" compatible and when are they not? Depending on the discipline, the approach for compatibility differs. In some cases compatibility can be explicitly verified; for instance, blood compatibility, compatibility of substances in chemistry or compatibility of web services. However, there are also objects whose compatibility cannot be clearly measured. Such a situation occurs in social science where compatibility is usually identified with 
similarity. We take the same approach for the issue of service compatibility and consider that the more similar the services, the more compatible they are. In this context compatibility of services is crucial because the value is generated only when compatible elements are consumed together, otherwise the utility of the totality is greatly reduced (Desruelle, Gaudet \& Richelle, 1996).

\section{MATERIAL AND METHODS}

In this section we present a method for determining the degree of service compatibility. However, before going into detail, it is important to discuss circumstances that make some services more amenable for compatibility assessment than others.

First of all, services are provided by various administrative bodies within distinct governmental levels. In Catalonia, Spain, public services are programmed by different entities at the State, Autonomous community, Province and Municipal level. Unfortunately, there is little cooperation between these bodies in terms of public services and facilities. Consequently, a facility building is usually a property of the entity that delivers the service. This imposes a separate approach for services and facilities provided by each governmental level, and dramatically reduces possible benefits resulting from shared use of space. Due to these circumstances theoretically compatible services that are administered by different authorities, in the real world, are not likely to be combined. For this reason, to make this research more realistic, we restrict application of the method to services that are exclusively a municipal responsibility.

Another limitation concerns sensitive services such as religious, safety or funeral services. These are services which, due to their character, should not be combined with others for safety or ethical purposes. For this reason all sensitive services have been excluded from our considerations.

Having applied the abovementioned restrictions, in the following sections we present the method of service description and a calculation of compatibility. 


\subsection{Service features}

A profound research on the system of municipal services provision has been conducted to find a universal way of service description and comparison. As a result, we propose a set of seven features that in our opinion characterize services in the best way and make them comparable. The features are as follows: Affiliation, Delivery, Nature, Presence, Scope, Stakeholder and User. Each of these features consists of attributes. Every attribute has a percentage value. The value can be either binary (in this case $0 \%$ or $100 \%$ because for legibility purposes, we present the results on a percentage scale) or relative (each attribute may have a different value from $0 \%$ to $100 \%$ ). It is important to stress that these values are compositional data - they always have to sum 1 (in this case 100\%) (Pawlowsky-Glahn \& Egozcue, 2006). In sections 2.1.1 - 2.1.7 all proposed features and attributes are described in detail.

\subsubsection{Affiliation}

Affiliation refers to the administration department responsible for providing a particular service. Thus, typical attributes of this feature are names of administration units e.g.: Recreation, Planning, Public works, etc. However, it is important to realize that administration departments are context-dependent. In consequence, the names and number of attributes can vary from one city to another, due to the different organization schemes. The value of attribute Affiliation is binary, because a particular service is affiliated to one, and only one, city department.

\subsubsection{Delivery}

The delivery feature has two relative attributes: back office and front office. Back office services are those that users do not interact with directly, for example general administration services. On the other hand, front office services are those where direct interaction with users takes place. They are open to the public, and citizen attention is an important part of the service. These are usually cultural, social or educational services.

\subsubsection{Nature}

Nature reflects how a service is seen by its users. It is in contrast to the Affiliation feature, which represents the administration perspective. For instance, a primary school service is affiliated to the Department of Education. Thus, it would be considered exclusively as an 
educational service by the administration. However, users may perceive it as a compilation of different domains such as social, culture, education, etc., rather than a single one. The Nature feature therefore consists of eight relative attributes: administration, culture, education, health care, safety, social, sports and transport.

\subsubsection{Presence}

The Presence feature refers to the way that the service is delivered to its users. We distinguish two attributes in this feature: in person and virtual. A traditional approach requires the physical presence of the user to deliver the service (in person). For example, in the case of a library service, a user has to visit the library facility to pick up and return a book. Nonetheless, recently, we can observe the process of services virtualization. Virtual services do not require a citizen's physical presence and can be, wholly or partially, delivered online. In person and virtual attributes are not mutually exclusive and therefore are relative: a service can be considered as in person in $\mathrm{x} \%$ and virtual in $\mathrm{y} \%$, respective to the number of users choosing each mode of access.

\subsubsection{Scope}

The scope feature refers to the distribution of the service across the city area. It has two binary attributes: a service can be either local or global. Global services are those that serve the whole city. There is only one instance of a global service in the city, usually located in a well accessible place in the city centre. Local services, on the other hand, are numerous. They are designed to serve local communities and are distributed across the city area, e.g. a district library.

\subsubsection{Stakeholder}

The Stakeholder feature specifies all persons who have an interest in a service and somehow participate in it. It is not limited to the service users but encompasses all groups of interest, such as: service staff members, parents who accompany their children to school, etc. This feature differentiates groups of stakeholders according to their age: children, youth, adults and the elderly. We use the following classification: children: 0-18 years; youth: 18-30, adults: 30-75; elderly: 75+, although any other can be used if appropriate. The Stakeholder

feature value is considered to be relative, because usually, representatives of various age groups are involved in a service. 


\subsubsection{User}

The User feature corresponds to the stakeholder one with the difference that it reflects the end-user perspective, while the stakeholder reflects the administration one. It refers exclusively to a person who directly interacts with a municipal service. Despite these differences, a user feature has the same set of relative attributes: children, youth, adults and the elderly.

All of the abovementioned features, together with their attributes, are summarized in table 2.

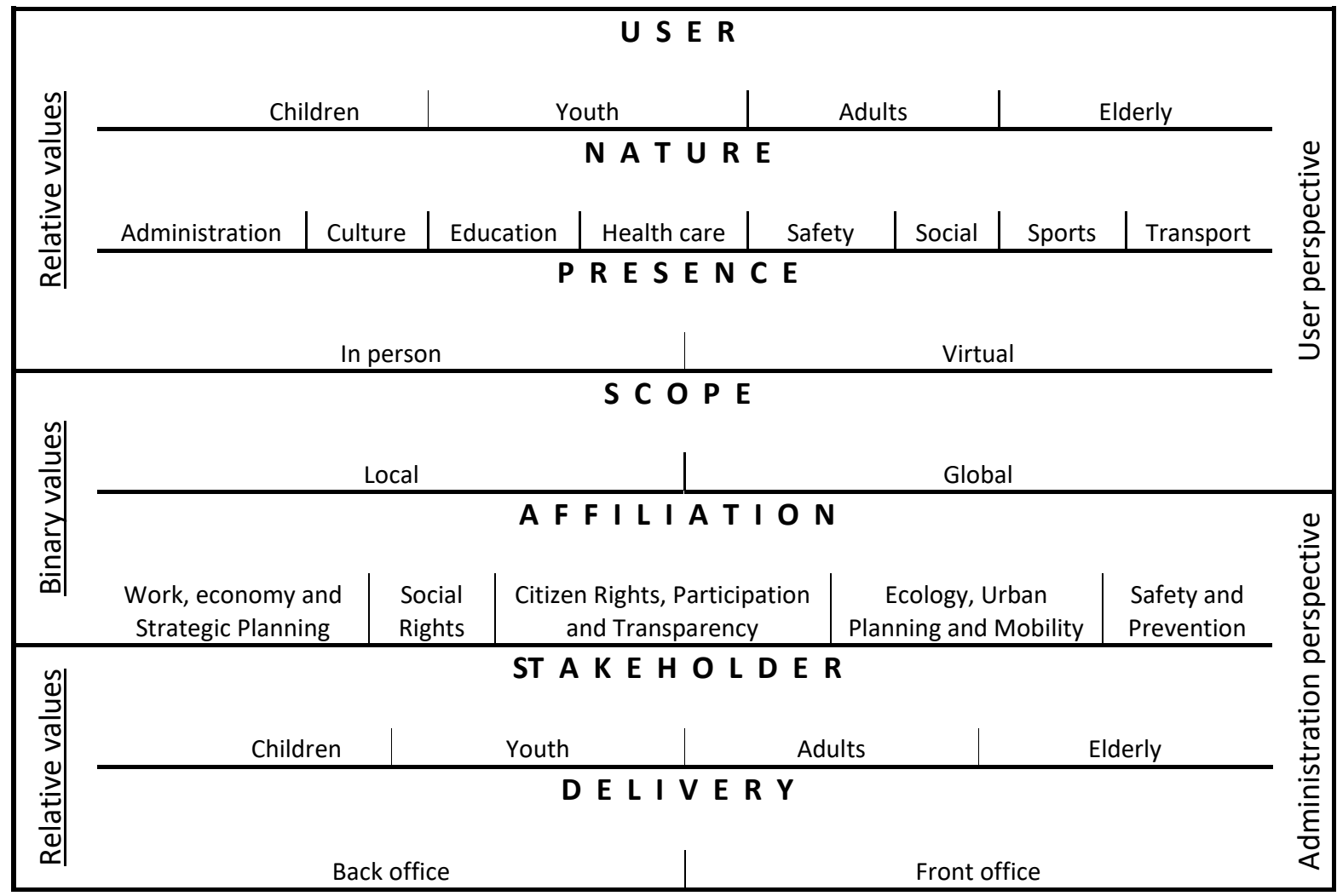

Table 2 A summary of service features with their attributes.

\subsection{Service compatibility}

To establish the degree of compatibility, it is necessary to describe every service in a quantitative way. The service description is carried out by filling in the attributes values for every feature. This task has to be done by either a service director or another person with a profound knowledge about the service and its context. Next, the services are organized in pairs. Service comparison comes down to the calculation of the distance between values of their attributes. For that purpose we take advantage of the City-block distance that represents 
a distance between two points as a sum of the absolute differences of their coordinates (Panigrahi, 2014). The general City-block distance formula is presented below:

$$
d=\sum_{i=1}^{n}|x i-y i|
$$

However, for the purpose of service comparison it has to be normalized and takes the following form:

$$
c(S 1, S 2)=100 \%-\left(\frac{1}{2} \sum_{i=1}^{n}|S 1 i-S 2 i|\right)
$$

where:

$c=$ compatibility

$\mathrm{S} 1=$ service 1

$\mathrm{S} 2=$ service 2

$\mathrm{n}=$ number of attributes

\section{RESULTS}

In this section we illustrate the method described above on a pilot project that has been conducted on 30 municipal services in the city of Girona, Spain. The sample contains a variety of services of different characteristics to replicate the diversity of the city environment. The complete list of the selected services is as follows:

1. Municipal Service of Territorial Analysis

2. Municipal Habitat Service

3. Council Tax Service

4. Service of Citizen Attention

5. Service of City Historical Archive

6. Service of Image Research and Dissemination 
7. Tourist Office Service

8. Municipal Employment Service

9. Library Service "Antònia Adroher"

10. School Library Service "Montfollet"

11. Public Library Service "Carles Rahola"

12. Catalan Language Promotion Service

13. Service of City History Museum

14. Civic Centre Service "Sant Narcís"

15. Municipal Market Service

16. Youth Centre Service "Els Quimics"

17. "La Caseta" Educational Service

18. Service of Municipal Music School

19. "l'Olivera" Nursery School Service

20. Service of Adult Education

21. Migdia Primary School Service

22. "Font de l'Abella" Service of Special Education

23. Service of Municipal School of Art

24. Santa Eugènia - Can Gibert del Pla District Swimming Pool Service

25. Santa Eugènia-Montfalgars District Sports Pavilion Service

26. Youth Health Service

27. "La Sopa" Homeless Shelter Service

28. Municipal Service Council of LGBT

29. Municipal Service Council for the Elderly

30. Service of Communication, Documentation and Marketing

Additionally, the distribution of all the abovementioned services over the city area was marked in illustration 1. 


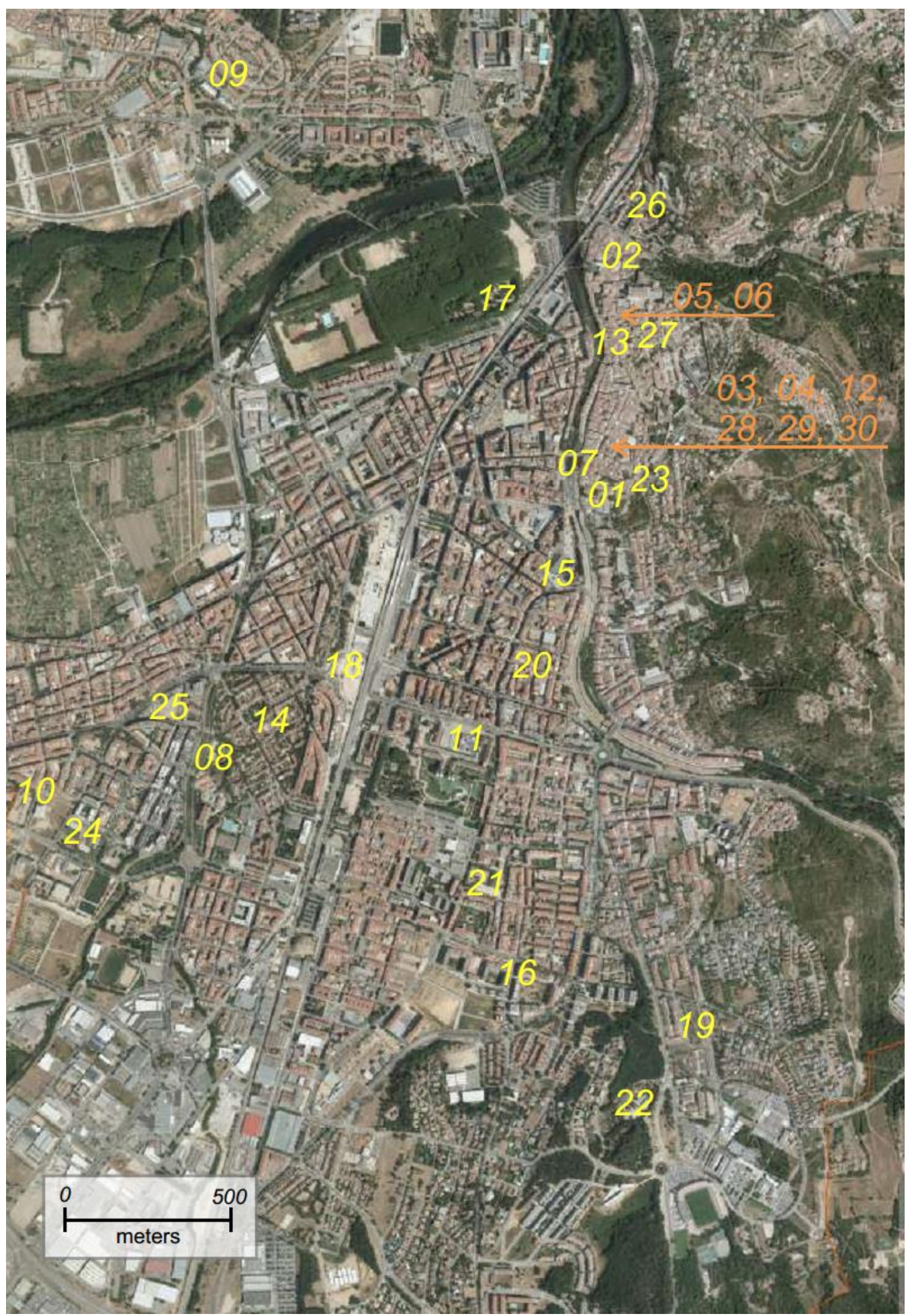

Illustration 1 Spatial distribution of 30 sample services. The numbers marked in orange with an arrow indicate services that are offered in the same facility. Services 03, 04,12, 28,29, 30 are hosted in the Town Hall. Source: Unitat Municipal d'Anàlisi del Territori, Girona.

Each service from the 30 selected has been described by filling in values of attributes for every feature. The result is presented in Table 3. Due to the volume limit, we present a 
description of only 3 out of all, 30 services.

\begin{tabular}{|c|c|c|c|c|}
\hline \multicolumn{2}{|r|}{ Service Name: } & $\begin{array}{c}\text { "I'Olivera" } \\
\text { Nursery School } \\
\text { Service }\end{array}$ & $\begin{array}{l}\text { Municipal } \\
\text { Service of } \\
\text { Territorial } \\
\text { Analysis } \\
\end{array}$ & $\begin{array}{l}\text { Migdia Primary } \\
\text { School Service }\end{array}$ \\
\hline Feature & Attribute & & Value & \\
\hline \multirow{4}{*}{ USER } & Children & $100 \%$ & $10 \%$ & $100 \%$ \\
\hline & Youth & $0 \%$ & $35 \%$ & $0 \%$ \\
\hline & Adults & $0 \%$ & $50 \%$ & $0 \%$ \\
\hline & Elderly & $0 \%$ & $5 \%$ & $0 \%$ \\
\hline \multirow{8}{*}{ NATURE } & Administration & $0 \%$ & $50 \%$ & $0 \%$ \\
\hline & Culture & $0 \%$ & $20 \%$ & $10 \%$ \\
\hline & Education & $5 \%$ & $30 \%$ & $70 \%$ \\
\hline & Health care & $0 \%$ & $0 \%$ & $0 \%$ \\
\hline & Safety & $0 \%$ & $0 \%$ & $0 \%$ \\
\hline & Social & $95 \%$ & $0 \%$ & $10 \%$ \\
\hline & Sports & $0 \%$ & $0 \%$ & $10 \%$ \\
\hline & Transport & $0 \%$ & $0 \%$ & $0 \%$ \\
\hline \multirow{2}{*}{ PRESENCE } & In person & $100 \%$ & $20 \%$ & $100 \%$ \\
\hline & Virtual & $0 \%$ & $80 \%$ & $0 \%$ \\
\hline \multirow{2}{*}{ SCOPE } & Local & $100 \%$ & $0 \%$ & $100 \%$ \\
\hline & Global & $0 \%$ & $100 \%$ & $0 \%$ \\
\hline \multirow{7}{*}{ AFFILIATION } & Office of the Mayor & $0 \%$ & $0 \%$ & $0 \%$ \\
\hline & Department of Citizens & $100 \%$ & $0 \%$ & $100 \%$ \\
\hline & Department of Urban Planning & $0 \%$ & $100 \%$ & $0 \%$ \\
\hline & Department of Finance and Sustainability & $0 \%$ & $0 \%$ & $0 \%$ \\
\hline & Department of Promotion and Employment & $0 \%$ & $0 \%$ & $0 \%$ \\
\hline & Department of Safety, Mobility and Public Space & $0 \%$ & $0 \%$ & $0 \%$ \\
\hline & Department of Social Services & $0 \%$ & $0 \%$ & $0 \%$ \\
\hline \multirow{4}{*}{ STAKEHOLDER } & Children & $60 \%$ & $5 \%$ & $60 \%$ \\
\hline & Youth & $10 \%$ & $40 \%$ & $15 \%$ \\
\hline & Adults & $25 \%$ & $50 \%$ & $20 \%$ \\
\hline & Elderly & $5 \%$ & $5 \%$ & $5 \%$ \\
\hline \multirow{2}{*}{ DELIVERY } & Back office & $10 \%$ & $90 \%$ & $10 \%$ \\
\hline & Front office & $90 \%$ & $10 \%$ & $90 \%$ \\
\hline
\end{tabular}

Table 3 Quantitative description of municipal services.

Next, all 30 services were organized in pairs based on the all-play-all rule. Applying the formula $\frac{n}{2}(n-1)$ for $\mathrm{n}=30,435$ pairs of services were obtained. Later, the normalized formula of the City-block distance was applied to calculate the service compatibility for every feature. To depict this calculus, let us consider the user feature of the "l'Olivera" Nursery School Service and the Municipal Service of Territorial Analysis. We take the values of attributes from table 3 and substitute them into the normalized City-block formula as follows:

$c(S 1, S 2)=100 \%-\left(\frac{1}{2}|100 \%-10 \%|+|0 \%-35 \%|+|0 \%-50 \%|+|0 \%-5 \%|\right)=$ 


$$
100 \%-\left(\frac{1}{2}(90 \%+35 \%+50 \%+5 \%)\right)=100 \%-\frac{180 \%}{2}=10 \%
$$

It turned out that in this case the compatibility degree is equal to $10 \%$ (a relatively low value). Subsequently, we calculate the compatibility of other features in the same way. The results obtained for all features provide an overview of compatibility between services.

Table 4 presents a result of a compatibility calculus for every feature between the "l'Olivera" Nursery School Service and 29 other sample services.

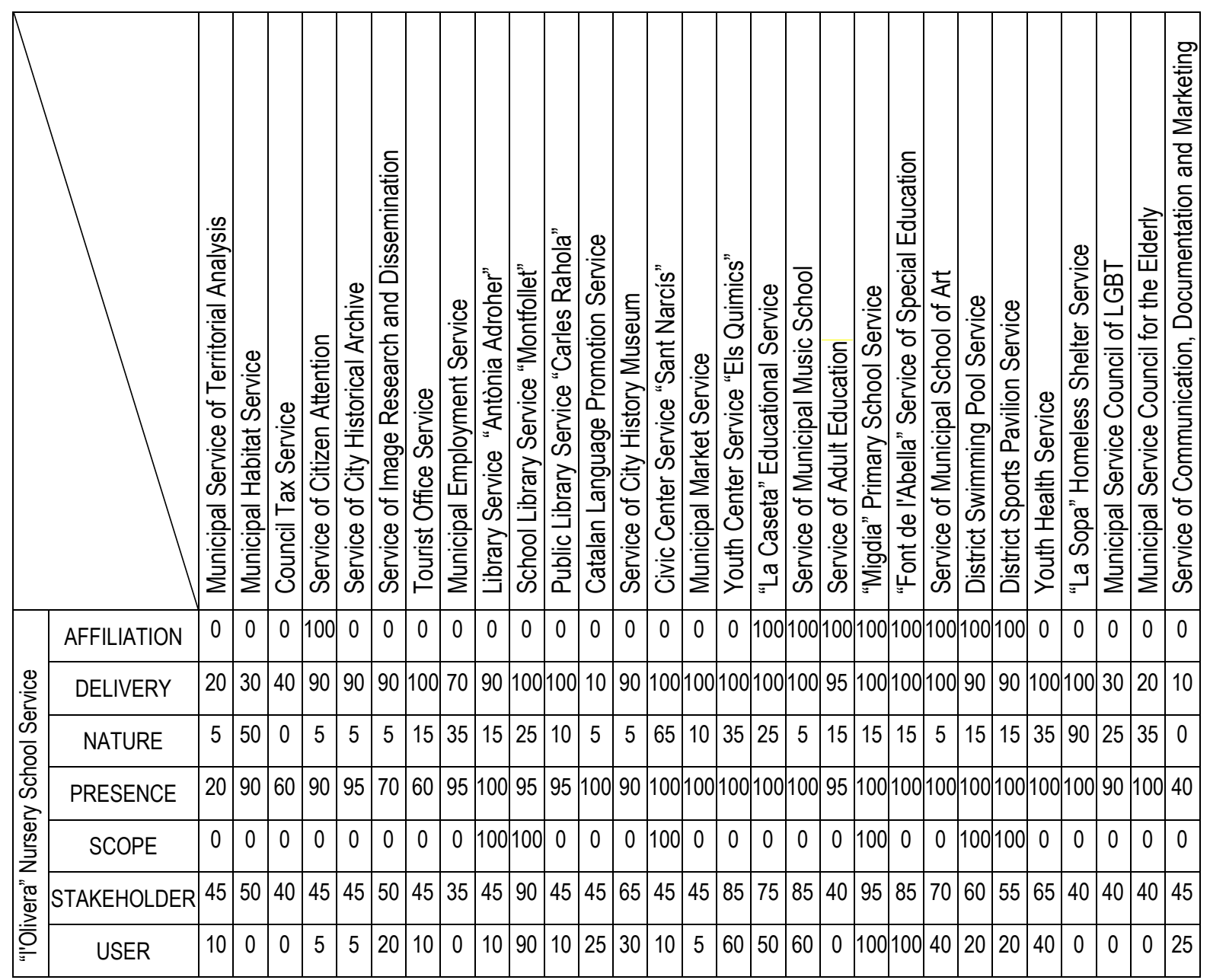

Table 4 Degree of compatibility for every feature between the "I'Olivera" Nursery School Service and 29 other sample services. All values in \%.

Next we present the results from table 4 in graphical form on radar charts that visualize the degree of compatibility for each feature clearly. Figures 1 and 2 illustrate two extreme cases showing respectively high (figure 1), and low compatibility degree (figure 2). 


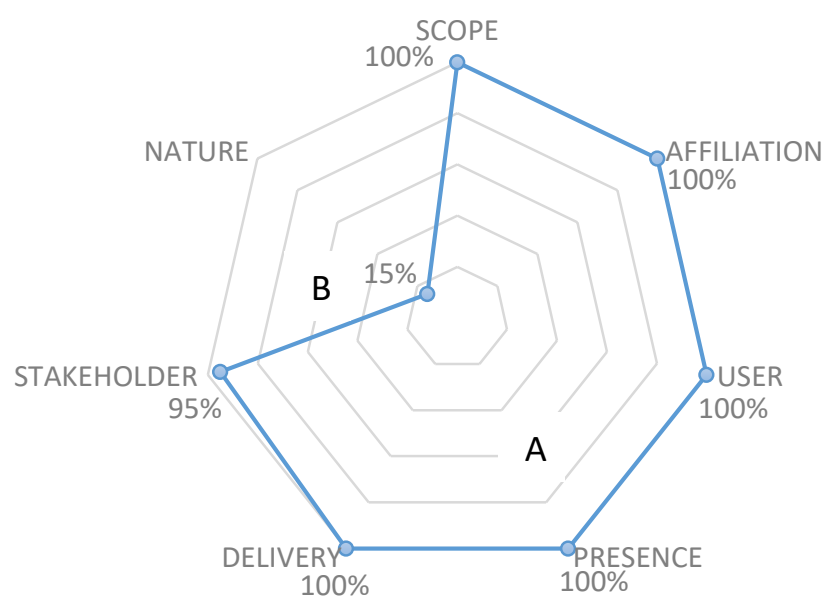

Figure 1 Graphical representation of compatibility between the "I'Olivera" Nursery School Service and "Migdia" Primary School Service.

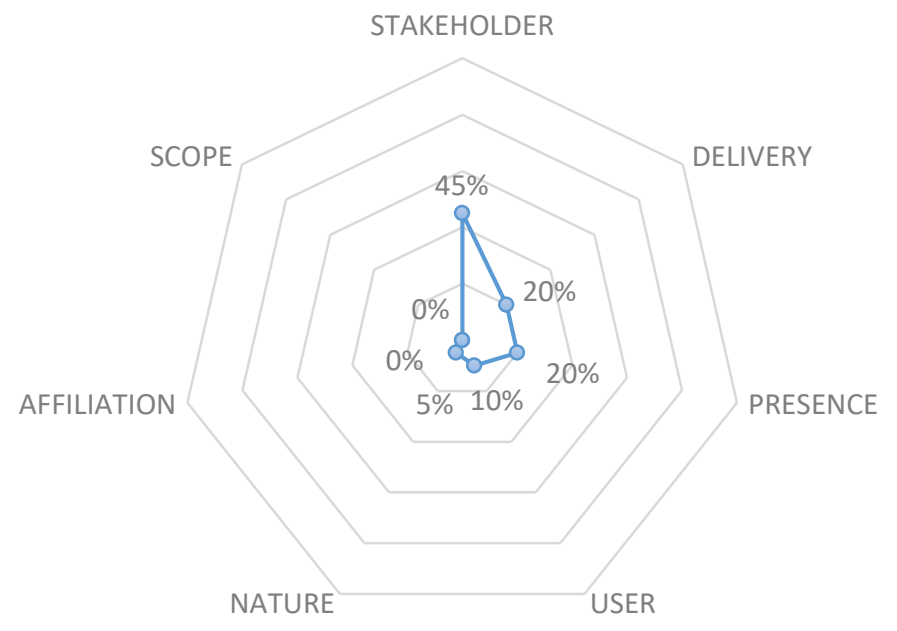

Figure 2 Graphical representation of compatibility between the "I'Olivera" Nursery School Service and Municipal Service of Territorial Analysis.

The features on the graphs are organized according to their values in descending clockwise order for the sake of legibility. Such a graphical representation shows a clear image of the areas in which services coincide and where they differ, helping to interpret the results. The plot in figure 1 covers almost the entire chart area reflecting high compatibility in every feature except the nature one, where the compatibility is equal to $15 \%$. This is because the 
Nursery School service is mostly considered as social, whilst the Primary School service is considered as educational (see table 3 ).

Figure 2 depicts an example of very low general compatibility, reaching the highest value of $45 \%$ in the Stakeholder feature. It is also clear that the plot covers only a small part of the entire chart showing that these two services have little in common.

Radar charts also play an important role in obtaining the total compatibility result expressed as the ratio of the area of two polygons: a regular heptagon of the edge $\approx 86,794$ (B, figure 1) and the polygon created by connecting values of every feature (A, figure 1). Total compatibility values for all 30 services are presented in table 5 . 


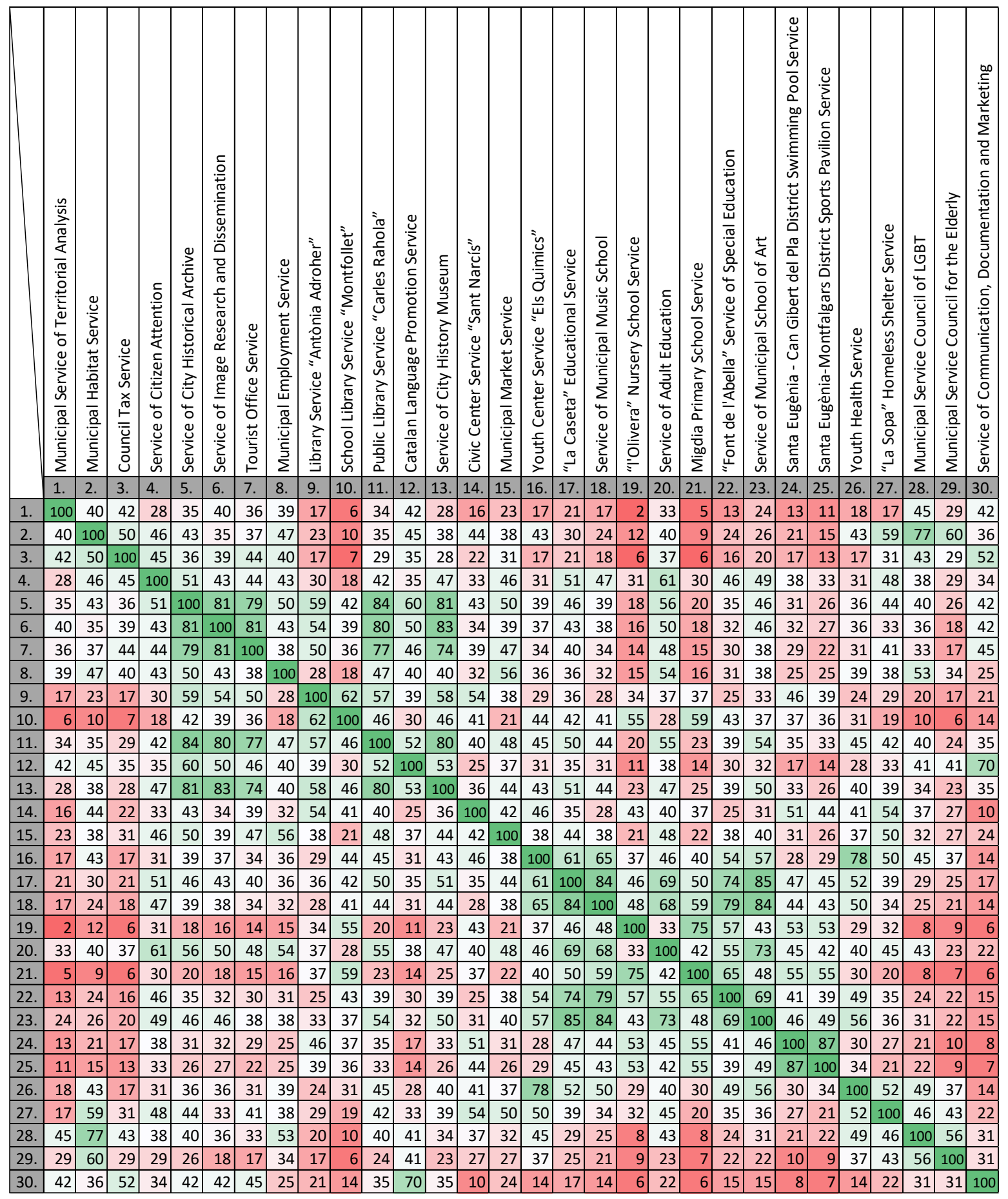

Table 5 Compatibility matrix for 30 sample services. All values in \%.

Table 5 presents the compatibility matrix that shows a total compatibility value between each pair of services. It shows that the most compatible are Santa Eugènia - Can Gibert del Pla District Swimming Pool and Santa Eugènia-Montfalgars District Sports Pavilion Service $87 \%$, whilst the least compatible are "l'Olivera" Nursery School Service and Municipal Service of Territorial Analysis - 2\%. 
Based on this matrix, we grouped the results into four sets: 1) Services with a result in the range between $100 \%$ and $75 \%$ are considered to be strongly compatible; 2) those in the range from $75 \%$ to $50 \%$ are of acceptable compatibility; 3 ) services with a result from $50 \%$ to $25 \%$ are of poor compatibility; and 4) services with a result in the range between $25 \%$ to $0 \%$ are considered to be incompatible. Next, we analysed the compatibility matrix, searching especially for groups of more than two services in every set. The results are as follows:

In the set of strongly compatible services we discovered two groups of four services:

- Tourist Office Service; Service of City Historical Archive; Service of Image Research and Dissemination and Public Library Service "Carles Rahola,

- Service of City History Museum; Service of City Historical Archive; Service of Image Research and Dissemination and Public Library Service "Carles Rahola, one group of three services:

- "La Caseta" Educational Service; Service of Municipal Music School and Service of Municipal School of Art,

and 16 other pairs of strongly compatible services.

In the set of acceptable compatibility we discovered one group of three services:

- Santa Eugènia-Montfalgars District Sports Pavilion Service; "l'Olivera" Nursery School Service and "Migdia" Primary School Service,

as well as 57 other pairs of services.

In the set of poor compatibility we discovered 260 pairs of services but not larger groups. Finally, in the last set of services considered to be incompatible we discovered one group of three:

- Service of City History Museum; "l'Olivera" Nursery School Service and Municipal Service Council for the Elderly,

as well as 102 other pairs of services.

Additionally, we used the compatibility assessment method to evaluate the services already offered under one roof. In illustration 1 we can see two cases of MSF. The first case is formed by the Service of City Historical Archive (05) and the Service of Image Research and Dissemination (06). Their compatibility is equal to $81 \%$. We can therefore consider this to 
be an example of a successful combination of strongly compatible services.

The other case is formed by six services that are offered in the Town Hall building: Council Tax Service (03), Service of Citizen Attention (04), Catalan Language Promotion Service (12), Municipal Service Council of LGBT (28), Municipal Service Council for the Elderly (29) and the Service of Communication, Documentation and Marketing (30). It transpired that this case is less advantageous. The extreme compatibility values are $70 \%$ for the Catalan Language Promotion Service and the Service of Communication, Documentation and Marketing. On the other hand, 29\% for two pairs of services: the Municipal Service Council for the Elderly and the Council Tax Service, as well as the Municipal Service Council for the Elderly and the Service of Citizen Attention. The average compatibility value calculated by arithmetic mean of all compatibility values for the six services (table 5) is equal to $41 \%$ $\left(\frac{45 \%+35 \%+43 \%+29 \%+52 \%+35 \%+38 \%+29 \%+34 \%+41 \%+41 \%+70 \%+56 \%+31 \%+31 \%}{15}\right)$. Thus we can consider the general compatibility of this combination of services as rather poor.

\section{DISCUSSION}

The presented method allows us to obtain a percentage value of compatibility between municipal services. However, there are some concerns that are important to recognize, and may have a substantial influence on the final results.

The most significant issue to stress is that service compatibility is context-sensitive. It cannot be considered in isolation without the surrounding environment. The context co-creates the service and is responsible for its unique character. However, the socio-political and economic environment changes in both, i.e. space and time. For this reason service compatibility is not transferable. Two services may be highly compatible in one city context, but corresponding services in another city may have a totally different compatibility value. A primary school service, for instance, is highly standardized. However, in spite of this, every instance of this service may have a different characteristic according to the context in which it is situated. This difference will translate in distinct attribute values and eventually the final compatibility result. For this reason we assess very specific service instances, instead of encapsulated 
categories of services. Similarly, service compatibility calculated today may change dramatically in years or even months to come, along with changes of the environment. This is why compatibility assessment should not be a one-time event, but rather a regularly repeated process.

Another important point is that the result of compatibility assessment is expressed as the area ratio of two polygons. We consider this way of calculation the most appropriate in general terms since it reflects well the extreme values. Yet again, depending on the particular city context, some features may be more important for the decision maker than others. In such cases another type of calculus, such as weighted arithmetic mean, may be considered more suitable.

Moreover, the features described in sections 2.1.1. - 2.1.7. are, in our opinion, the most important ones and appropriate for the purpose of defining service compatibility. However, the method is flexible, thus the number of features, as well as the number and type of attributes (binary/relative) can be modified according to the current needs and context requirements. Such changes do not affect the model, and the way of calculating the compatibility remains the same.

\section{CONCLUSIONS}

Municipal service provision is a key aspect of city management. However, recent literature suggests that they are not sustainable and their performance should be optimized. This optimization should begin from the appropriate adjustment of the surface available in facilities to the spatial needs of services. For this reason, our focus was on the issue of

municipal services compatibility for the sake of their efficient combination in Multi - Service Facilities.

First, we defined two fundamental concepts: a service and a facility. We described them and stressed the difference, summarizing that, in short, a service is an intangible content of a physical container - facility. Next, three types of relationships between services and facilities 
were identified: 1) one service offered in one facility; 2) one service offered in various facilities; 3) various services offered in one facility (MSF).

Subsequently, we proposed a method of calculating the degree of compatibility between municipal services. The method comes down to the service description via seven features (Affiliation, Delivery, Nature, Presence, Scope, Stakeholder and User), and posterior calculus of their values applying the City-block distance formula. The proposed method has been tested on a pilot project with 30 services from the city of Girona. Each service was described quantitatively. Next, the compatibility of each service with each one was calculated using a normalized City-block formula. The compatibility results were illustrated graphically on the radar charts and the total compatibility results were presented in the compatibility matrix. Subsequently, the results were grouped into four sets depending on their degree of compatibility, from services strongly compatible to those that are incompatible. Posteriorly the method of calculating the degree of compatibility was also used to evaluate two identified cases of MSF indicating strong compatibility in the first case and poor compatibility in the other. Doing this, we positively verified the hypothesis stated at the beginning of this article, confirming that it is indeed possible to establish the degree of compatibility between municipal services.

Moreover, we came to the conclusion that MSF is a desired solution for the optimization of city resources. It allows a more efficient land usage and always creates added value when combined services are compatible, one to another. The value is created in two ways: by decreasing the cost of service provision (the administration perspective) and increasing the quality (end user perspective).

The municipal administration may save money due to a more efficient facility usage increasing the occupancy rate. This reduces the energy consumption and maintenance cost. Well combined services and more efficient facility usage may render new facility construction unnecessary. Moreover, shared facility use requires less staff to maintain. It may also simplify logistical processes, especially in services where exchange of information and/or objects is frequent and essential.

On the end user side, the value added is created due to the user-friendly arrangement of services. Thanks to this, citizens can use more than one service during the same visit. They 
also spend less time on travelling from one facility to another. This positively impacts the city traffic as well as other related areas such as parking and technical utilities.

In summary, in this article our focus was on the compatibility of municipal services for the purpose of their advantageous combination in Multi-Service Facilities. However, the problem domain is very extensive and the possibilities of public facilities and services performance improvement are much broader. Therefore, we theorize that the framework application should be parallel with other e-government initiatives, especially the process of public services virtualization that contributes to spatial efficiency. Additionally, the use of the presented method is not limited exclusively to municipal services, but can be adapted and applied to any kind of services. In particular, we postulate future extension of this exercise by including private sector services that could be offered together with public ones, to support the public-private partnership.

ACKNOWLEDGEMENTS

This research has been conducted with the financial support of the Secretaria d'Universitats i Recerca del Departament d'Economia i Coneixement de la Generalitat de Catalunya [grant number: 2014 FI_B00971].

Besides the founding institution, the authors wish to acknowledge the help provided by Dr. Joaquim Melendez Frigola for his insightful comments and encouragement, as well Dr. Josep Antoni Martín-Fernández for his advice on compositional data. 


\section{REFERENCES}

Batty, Michael, Besussi, Elena, Maat, Kees, and Jan J. Harts (2004), “Representing Multifunctional Cities: Density and Diversity in Space and Time," Built Environment, 30(4), 324-337.

Bennett J, Iossa E (2006), "Building and managing facilities for public services.” Journal Of

Public Economics, 90(10-11), 2143-2160. doi:10.1016/j.jpubeco.2006.04.001.

Compatibility (2015), Retrieved July 27, 2015, from

http://www.oxforddictionaries.com/definition/english/compatibility

Cosgrave, Ellie, Tryfonas, Theo and Tom Crick (2014), “The Smart City from a Public Value Perspective,” In ICT for Sustainability 2014 (ICT4S-14). Atlantis Press.

Desruelle, Dominique, Gaudet, Gerard, and Yves Richelle (1996), “Complementarity, coordination and compatibility: the role of fixed costs in the economics of systems," International Journal of Industrial Organization, 14 (1996), 747-768.

Dobbelsteen van den, Andy and Sebastian de Wilde (2004), "Space use optimisation and sustainability—environmental assessment of space use concepts," Journal of Environmental Management, 73(2), 81-89,

Gonzalez, Reyes, Llopis, Juan, and Jose Gasco (2013), “Innovation in public services: The case of Spanish local government,” Journal of Business Research, 66(10), 2024-2033.

Kwok, W. L. Arnold and Clive M. J. Warren (2005), “Optimisation of performance in facilities management," Conference paper delivered at the Pacific Rim Real Estate Society Conference, Melbourne 24-27 January 2005.

Lee, Jungwoo and Hyejung Lee (2014), “Developing and validating a citizen-centric typology for smart city services," Government Information Quarterly, 31, S93-S105. 
Marsal-Llacuna, Maria-Lluisa, Leung, Y. Tat and Guang-Jie Ren (2011), “Smarter urban planning: match land use with citizen needs and financial constraints," In Computational Science and Its Applications-ICCSA 2011 (pp. 93-108). Springer.

Neirotti Paolo, De Marco, Alberto, Cagliano, Anna Corinna, Mangano, Giulio and Scorrano, Francesco (2014), "Current trends in Smart City initiatives: Some stylised facts," Cities, 38, 25-36.

Panigrahi, N. (2014), Computing in Geographic Information Systems. CRC Press.

Pawlowsky-Glahn, Vera and Juan-Jose Egozcue (2006), "Compositional data and their analysis: an introduction," Geological Society, London, Special Publications, 264(1), 1-10.

Tan, Yigitcanlar, Velibeyoglu, Koray and Scott Baum (2008), Creative Urban Regions: Harnessing Urban Technologies to Support Knowledge City Initiatives: Harnessing Urban Technologies to Support Knowledge City Initiatives. New York: IGI.

Thacker, Mike (2009), "Standards for classifying services and related information in the public sector," SCRAN Research Brief No.5. Retrieved from http://www.smartcities.info/files/Smart_Cities_Research_Brief_Standards_for_classifying $\underline{\text { services_and_related_information.pdf }}$

World Bank (2015) “Definition of E-Government” Retrieved December 27, 2015, from http://web.worldbank.org/WBSITE/EXTERNAL/TOPICS/EXTINFORMATIONANDCO MMUNICATIONANDTECHNOLOGIES/EXTEGOVERNMENT/0,,contentMDK:205071 53 menuPK:702592 pagePK:148956 piPK:216618 theSitePK:702586,00.html

Zolnik, Edmund, Minde, Julie, Gupta, D. Das and Sidney Turner (2010), “Supporting planning to co-locate public facilities: A case study from Loudoun County, Virginia," Applied Geography, 30(4), 687-696. 